\title{
علاقة أصول الفقه بالقرآن الكريم وعلومه
}

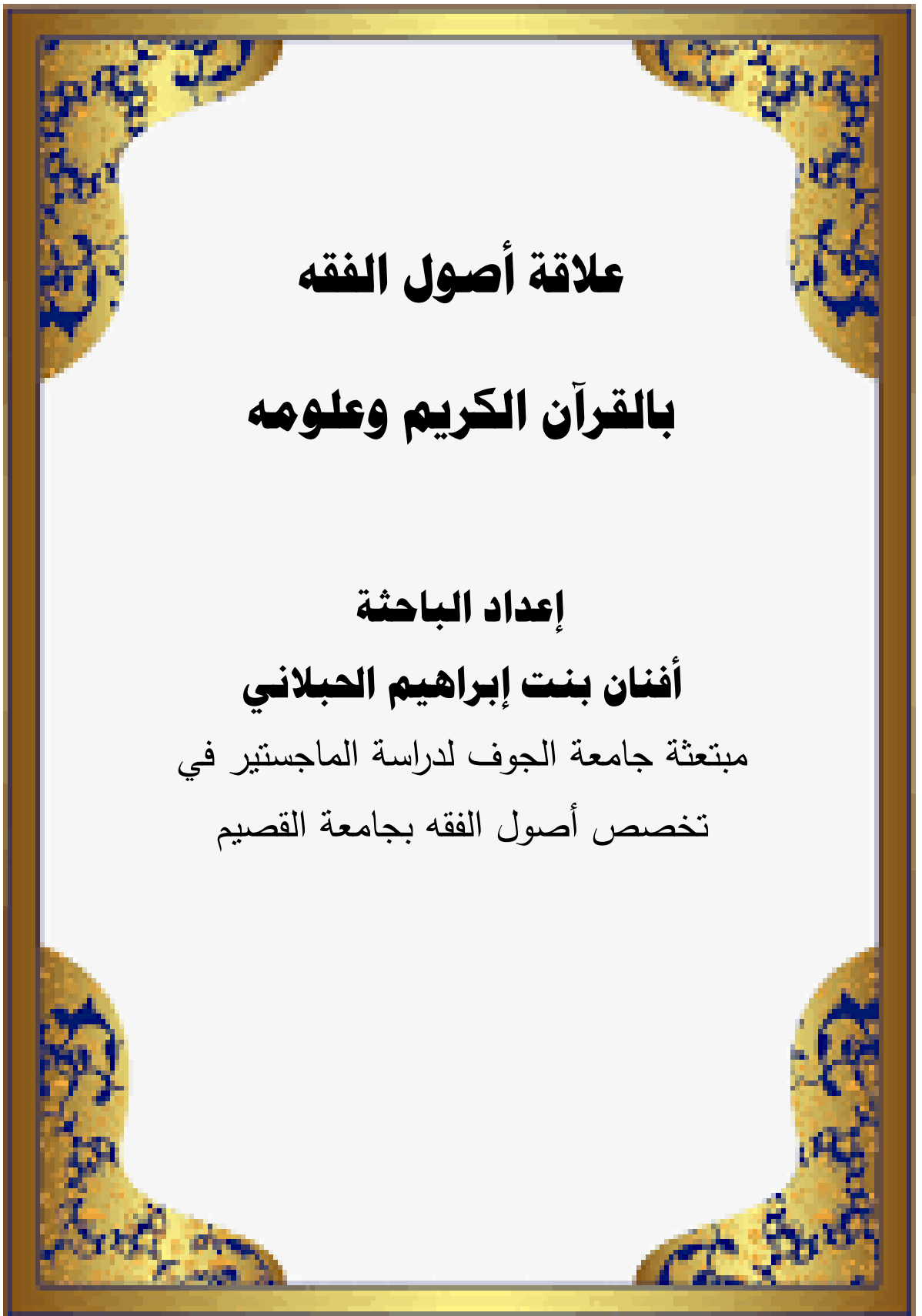




\section{علاقة أصول الققه بالقرآن الكريم وعلومه}

\section{علاقة أصول الفقه بالقرآن الكريم وعلموهـه}

$$
\text { أفنان بنت إبراهيم الحبلاني }
$$

مبتعثة جامعة الجوف لدراسة الماجستير في تخصص أصول الفقه بجامعة القصيم

$$
\text { البريد الإلكتروني: afnan-alhablani@hotmail.com }
$$

هذه الدراسة توضح منانة علاقة أصول الفقه بالقرآن الكريم وعلومه من أوجه عديدة؛ وقد سَلَكَتْ الدراسة في عرض مادتها منهجا استقرائيا تحليليا، وتوَّصلتُ إلى أن علاقة علم أصول الفقه بالقرآن الكريم تتلخَّص في: استمداده من القرآن الكريم، واشتماله على مباحث متعددة متعلقة بالقرآن الكريم، وأهميته في فهم نصوص القرآن الكريم، والاستتباط منها. كما توصنَّتنْ في علاقة علم الأصول بعلوم القرآن إلى أنَّها تتنظم في: تعلُّق العلمين بالنص القرآني، واشثراك العلمين في كثير من المباحث، وكون معرفة علم أصول الفقه شرطا في تفسير القرآن. كلمات مفتاحية: علاقة؛ أصول الفقه؛ القرآن الكربم؛ علوم القرآن. 


\section{علاقة أصول الفقه بالقرآن الكريم وعلومه}

\section{The relationship of the origins of jurisprudence to the Qur'an and its sciences}

Afnan Bint Ibrahim Al , Hablani

Al-Jouf University scholarship to study master's degree in the specialty of jurisprudence at Qassim University

E-mail: afnan-alhablani@hotmail.com

\section{Abstract:}

This study demonstrates the strength of the relationship between the principles of jurisprudence and the Holy Qur'an and its sciences from many aspects. In the presentation of its material, the study took an inductive and analytical approach, and concluded that the relationship of jurisprudence to the Holy Qur'an is summarized in: its derivation from the Holy Qur'an, and its inclusion of multiple topics related to the Holy Qur'an, and its importance in understanding the texts of the Holy Qur'an, and deduction from them.

It also concluded in the relationship of the science of origins with the sciences of the Qur'an that they are organized in: the two sciences are attached to the Qur'anic text, the two sciences participate in many investigations, and the knowledge of the science of jurisprudence is a condition in the interpretation of the Qur'an.

Keywords: relationship; Usul al-Fiqh; The Holy Quran; Quran Sciences. 


\section{علاقة أصول الققه بالقرآن الكريم وعلومه}

بسم الله الرحمن الرحيم

\section{مقدمة البحث}

الحمد لله رب العالمين، الرحمن الرحيم، والصلاة والسلام على نبينا

محمد، وعلى آله وأصحابه الطيبين الطاهرين، ومن تبعهم بإحسان إلى

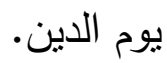

$$
\text { أما بعد }
$$

فإنَّ الناظر في العلوم الثرعية -من علوم القرآن، وعلوم الحديث، والعقبدة، والفقه والأصول، و... - سيلاحظ ارتباطها جميعا بالقرآن الكريم، بناء على أنه المصدر الأساسي والأولي في جميع هذه العلوم؛ وأن جلَّ الهدف في جميع هذه العلوم خدمة النص القرآني، توثيقا، واستمدادا، وتفسيرا، وبيانا؛ وهذا ما شكَّل قواسم مشتركة، وعلاقات منينة بين عدد من العلوم الإسلامية والمعارف الثرعية في أصولها، ومبادئها، وقواعدها، ومصطلحاتها، ومسائلها، وغير ذلك؛ ولهذا يقول العلامة أبو محمد ابن حزم الظاهري: "إن العلوم كلها متعلق بعضها ببعض، ومحتاج بعضها إلى بعض"('). وإنَّ من أهم هذه العلوم: علم أصول الفقه، الذي يعد من أبرز العلوم التي شكلت محورا تقاطعت فيه مجموعة من العلوم، حيث وظفت فيه عدة معارف، واستثمرت فيه عدة مفاهيم مما أهَّله لأن يكون علما جامعا بين العلوم النقلية والعلوم العقلية، وبين علوم الفهم وعلوم الاستدلال، وعلوم الثربعة وعلوم

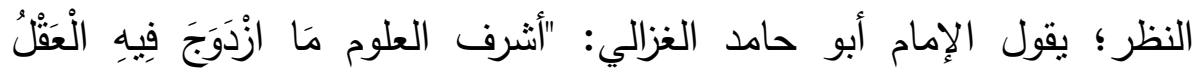

$$
\text { (1) (1 رسائل ابن حزم الأندلسي (رسالة مراتب العلوم) ؟/.9. }
$$




\section{علاقة أصول الققه بالقرآن الكريم وعلومه}

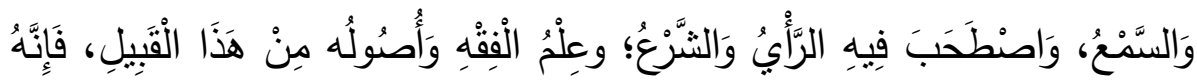

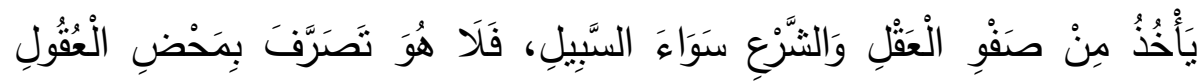

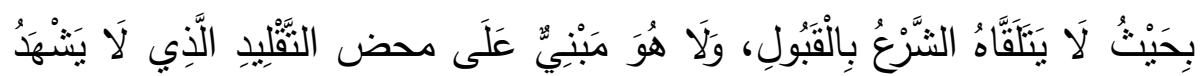

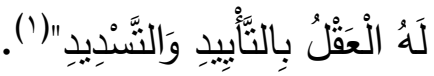
وأكتفي هنا بالاستشهاد على مركزية علم أصول الفقه بين العلوم العقلية

والنقلية، وقوة اتصاله بجميع العلوم على ما ذكره الزركثي، قائلا: "ففيه:

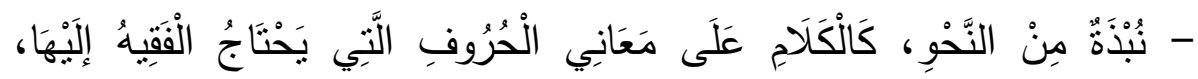

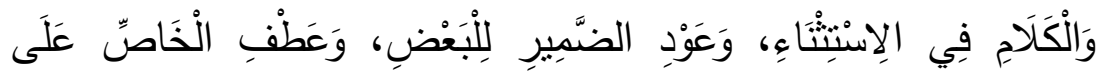
الْعَامِّ وَنَحْوِهِ.

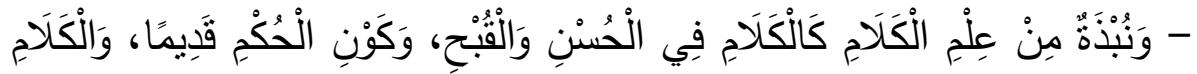

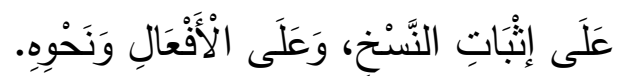

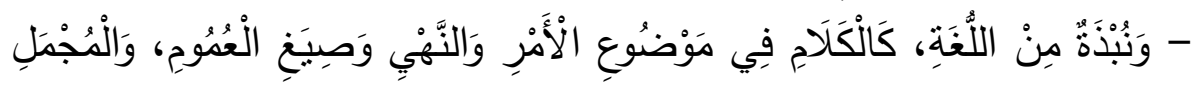

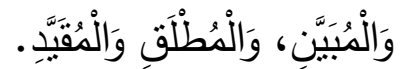

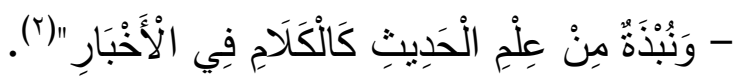
ولم يقتصر علم أصول الفقه في تداخله مع العلوم على العلوم الثرعية واللغوية فحسب، بل شمل حتى العلوم التجريبية، والاجتماعية؛ يقول الدكتور عطية: "إن في علم الأصول مباحثَ تصلح أن تكون نبراسًا ومعيارًا للعلوم الاجتماعية ومناهجها، وبالتحديد في تحليل الظواهر الاجتماعية، وبيان علاقات السببية بينها؛ منها مبحث العلة، ومنها أيضًا مبحث ما يسمى بالأحكام

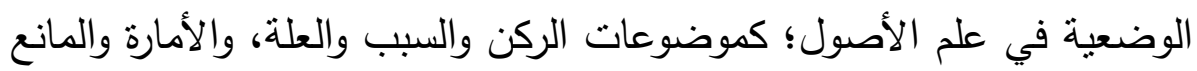

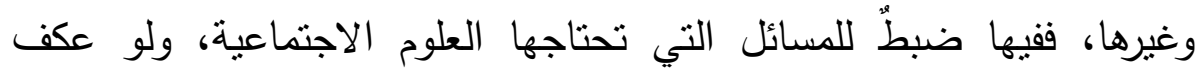

$$
\begin{aligned}
& \text { (1) المستصفى للغزالي ص: ع. }
\end{aligned}
$$

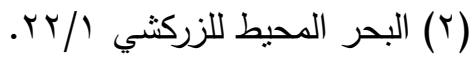




\section{علاقة أصول الققه بالقرآن الكريم وعلومه}

علماء الاجتماعيات على هذه المباحث، لوجدوا فيها كنوزًا تُعينهم في ضبط

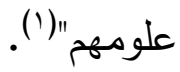

وقد لاحظ مركزية أصول الفقه بين العلوم كثيرٌ من الباحثين، فقرروها

في مصنفاتهم؛ يقول الأستاذ الدكتور حمد حمدي الصاعدي: "فإذا أدرك الباحث أبعاد هذا العلم [علم أصول الفقه] يجده متصدًّل بجميع العلوم الشرعية،

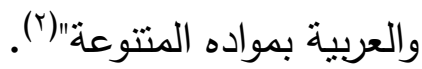

وسيجد القارئ الكريم نموذجا واقعيا لقوة اتصال علم أصول الفقه

وعلاقته ببقية العلوم في هذا البحث المخصص لكثف علاقته بالقرآن الكريم،

وعلومه.

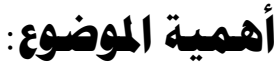

ا - لأهمية العلوم التي يتعلق بها هذا الموضوع؛ وهي: القرآن الكربم، وعلومه،

$$
\text { وعلم أصول الفقه. }
$$

ץ- ما تشكله العلاقة بين العلوم من أهمية قصوى في تقرير وحدة المرجعية

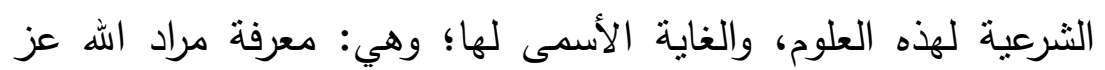
وجل، للوصول إلى عبوديته المؤدية إلى سعادة الدنيا والآخرة. r- ظهور علم أصول الفقه كقوة مؤثرة في ضبط فهم نصوص القرآن الكريم، وفنّ علوم القرآن، وتتابع العلماء على ترسيخ هذا المفهوم تصريحا وإعمالا؛ مما يستدعي إبراز هذا التأثير من خلاءل كثف العلاقة بينها.

1 - بيان العلاقة بين أصول الفقه والقرآن الكربم.

(1) تجديد أصول الفقه: دراسة تحليلية نقدية لمحاولات المعاصرين، لزكي الميلاد، صVV (1) $.1 \vee \wedge$ 。 (Y) المطلق والمقيد للاكتور حمد بن حمدي الصاعدي ص: ^. 


\section{علاقة أصول الفقه بالقرآن الكريم وعلومه}

r- بيان العلاقة بين أصول الفقه وعلوم القرآن.

r- كثن أثز علم أصول الفقه في علوم القرآن الكريم.

ع - كثف حاجة بعض العلوم إلى بعض.

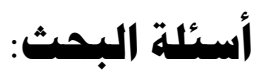

1- ما نوع العلاقة بين أصول الفقه والقرآن؟

r- ما نوع العلاقة بين أصول الفقه وعلوم القرآن؟

يتكون البحث من مقدمة، وتمهيد، ومطلبين، وخاتمة، وفهارس.

المقدهة: فيها الافتتاحية، وأهمية الموضوع، وأهدافه، وخطته، ومنهجه.

التمهيد: في توضيح هفردات البحث.

الاملب الأول: علاقة أصول الققه بالقرآن الكريم. فيمان.

الاملب الثاني: علاقة أصول الفقه بعلوم القرآن.

خاتهة: وفيها أهم النتائج والتوصيات.

فهارس: ويتكون من فهرس المصادر والمراجع، وفهرس الموضوعات.

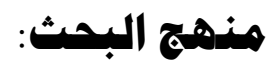

سلكتُ في هذا البحث منهجًا استقرائيَّا تحليليَّا حسب التفصيل الآتي:

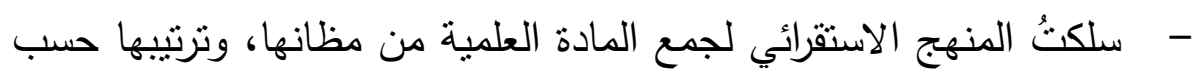

$$
\text { فقرات الخطة. }
$$

- وسلكتُ المنهج التحليلي لكثف مدى العلاقة بين أصول الققه وبين القرآن

$$
\text { الكربم وعلومه. }
$$

- التزمتُ بالمنهج العلمي المعهود في عزو الآيات القرآنية، والأحاديث النبوية، وتوثيق النقول، مع الالتزام بوضع علامات الترقيم، وضبط ما يحتاج

$$
\text { إلى ضبط. }
$$




\section{تمهيد: في توضيح هفردات البحث

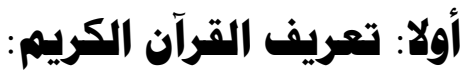

عُرِّف القرآن الكريم بتعريفات عديدة، ولعلَّ كثرة خصائص القرآن الكريم

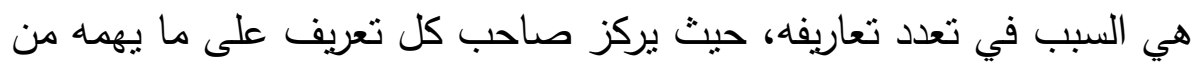

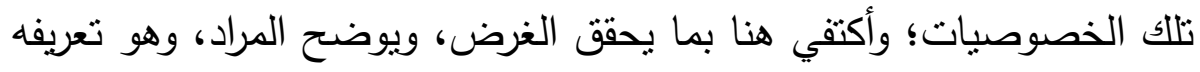

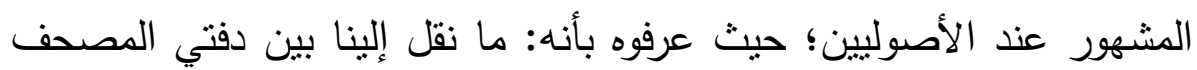

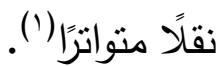

\section{ثانيا: تعريف أصول الفقهه باعتبار هعناه اللقبي:}

جرت عادة العلماء والباحثين على تعريف المركب الإضافي باعتبارين؛

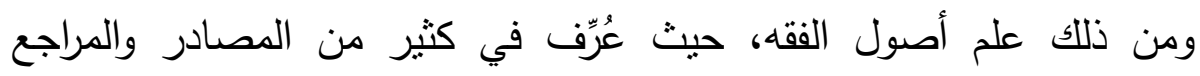

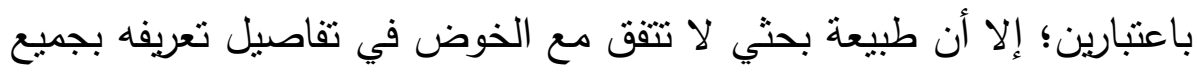
الاعتبارات الدذكورة؛ ولهذا سأكتفي بما يهمنا هنا، وهو تعريفه باعتبار معناه

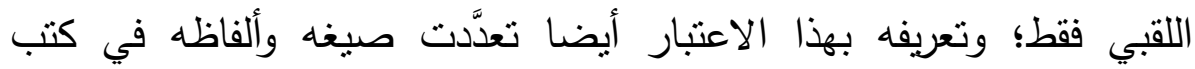

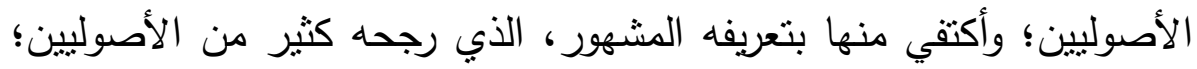
وهو: العلم الذي ييحث في أدلة الفقه الإجمالية، وكيفية الاستفادة منها، وحال المستقبد (r) (العو

(1) روضة الناظر لابن قدامة /99/، وينظر للوقوف على تعريفات متقاربة مع الثرح

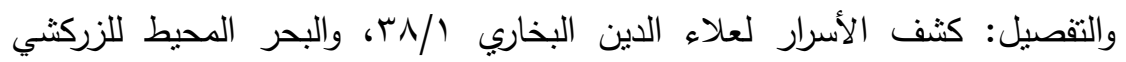

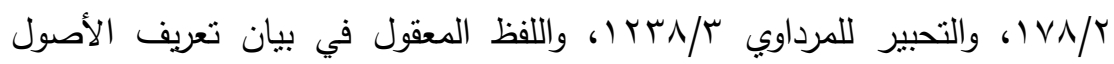

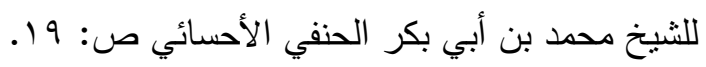

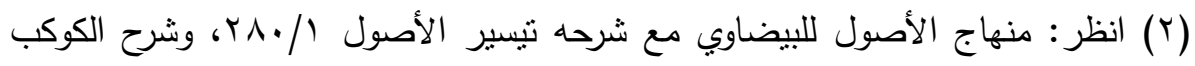

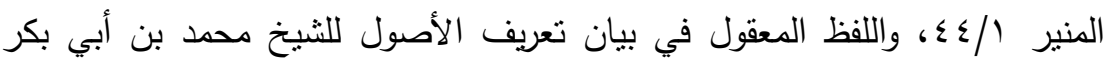

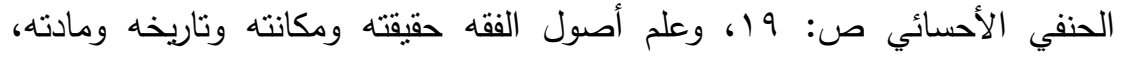

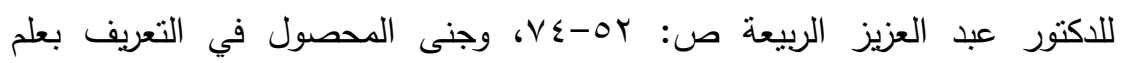

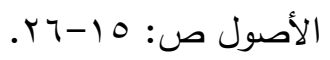




\section{علاقة أصول الققه بالقرآن الكريم وعلومه}

\section{ثالثا: تعريف علوم القرآن باعتبار همناه اللاقبب:}

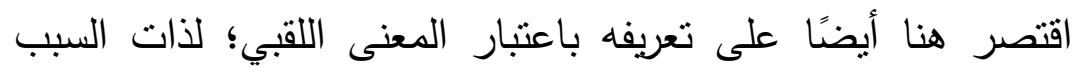

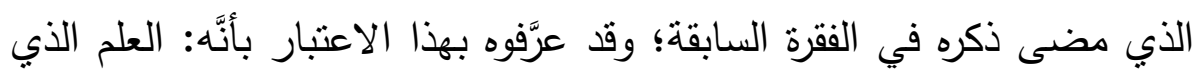
يبحث فيه عن المباحث المتعلقة بالقرآن الكريم من ناحية نزوله، وترتيبه، وجمعه، وكتابته، وقراءته، وتفسيره، وإعجازه، وناسخه ومنسوخه، ودفع الثبه باهن

عنه، ونحو ذلك (').

وذكر بعض الباحثين أن هذا العلم يسمى أيضا بـ"أصول التفسير"؛ لأنه

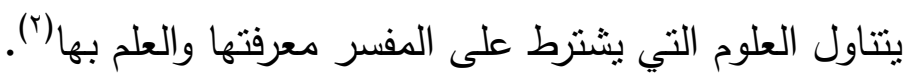
ورأى آخرون وجود فرق بين العلمين، وفسَّروا علم أصول التفسير بأنه

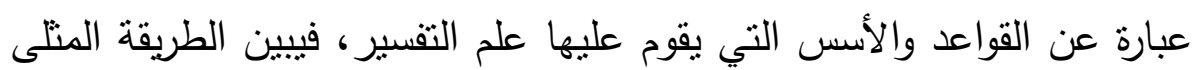
في شرح كلام الله وتفسيره(r). وبناء على هذا التعريف ومقارنته بما تقدم من تعريف علوم القرآن، رأى هؤلاء أن بين علوم القرآن وأصول التفسير عموما وخصوصا؛ فعلوم القرآن علم عام يدخل فيه أصول التفسير، بينما علم أصول التفسير خاص؛ وقد ضم بعض العلماء مباحث علم أصول التفسير ضمن علوم القرآن كالزركثي في البرهان، والسيوطي في الإتقان. وهناك من العلماء من رأى جواز إطلاق أصول التفسير على علوم القرآن من باب إطلاق الجزء على الكل. وقال بعضهه: وقد يسمى فنٌّ علوم القرآن بأصول التفسير؛ لأنه يتتاول

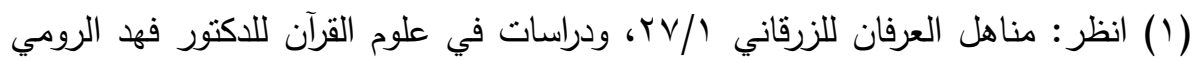

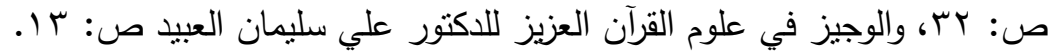

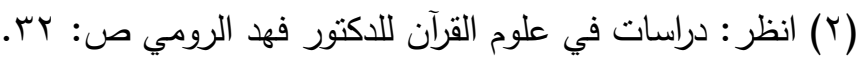

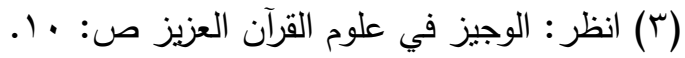




\section{علاقة أصول الققه بالقرآن الكريم وعلومه}

المباحث التي لا بد للمفسر من معرفتها للاستناد إلبها في تفسير القرآن؛ وهو

من مهمات علم أصول التفسير (').

رابعا: تعريف العلاقة:

يقول ابن فارس رحمه الله: العين واللام والقاف أصل كبيرٌ صحيح

يرجع إلى معنى واحد؛ وهو أن يُناط الشيء بالثيء، ويتصل به؛ قال الخليل:

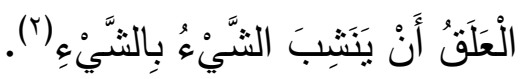

والمراد بالعلاقة في الاصطلاح العام لا يختلف عن المعنى اللغوي

كثيرا؛ يقول أبو البقاء الكفوي: العِلاقة تستعمل بفتح العين وكسرها؛ فالمفتوح يستعمل في الأمور الذهنية، والمكسور في الأمور الخارجية؛ فالعلاقة -بالفتحعلاقة المحبة والخصومة ونحوهما؛ وهي اتصال ورابطة ما بين الثيئين، أو الثخصين، ويعتبر بحسب قوة الاتصال (r). خلاصة المراد بعنوان البحث: بعد استعراض تعريف مفردات عنوان البحث، يمكن تلخيص المراد به، بأنه يبحث فيه عن أوجه اتصال علم أصول بعون الفقه وارتباطه بالقرآن الكريم وعلومه.

* $\quad * \quad * \quad * \quad * \quad *$

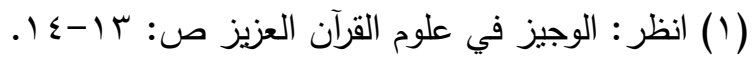

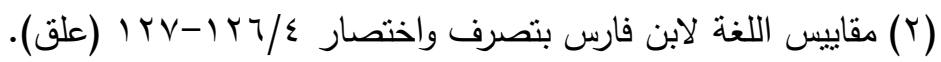

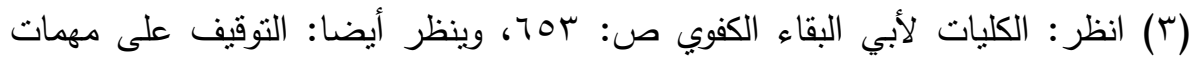

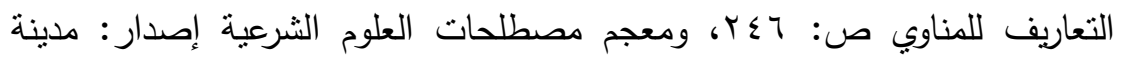

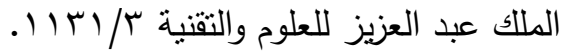




\section{علاقة أصول الفقه بالقرآن الكريم وعلومه}

\section{الاطبب الأول}

\section{علاقة أصول الفقه بالقرآن الكريم}

إنَّ علاقة علم أصول الققه بالقرآن الكريم علاقة راسخة ورابطة متينة؛

وسأتعرض لبعض أهم جوانب تلاك العلاقة في الفروع الأربع التالية:

الفرع الأول: استهمداد علم أصول الفقه هن القرآن الكريم:

إنَّ اعتماد علماء علم أصول الفقه في تقربر مسائلها على القرآن

الكريم، واستمدادها منه أمرُ بدهيٌ، لا يحتاج إلى عناء وجه في الإثبات؛

ويمكن لأي باحث ملاحظة ذلك عيانا بمجرد الرجوع إلى كتب أصول الفقه، حيث سيجد أنها مليئة بالاستدلال على المسائل الأصولية بالآيات القرآنية؛

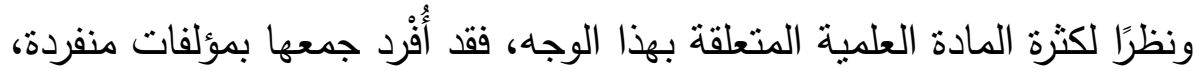

ومشاريع علمية مستقلة؛ وسأذكر هنا بعضها بغرض التمثيل دون الحصر: - - كتاب الإشارات الإلهية إلى المباحث الأصولية، تأليف: نجم الدين

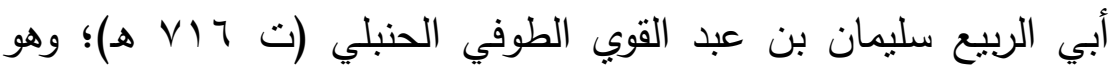
كتاب مطبوع ومتذاول.

- - استدلال الأصوليين بالكتاب والسنة على القواعد الأصولية، تأليف: الدكتور عياض السلمي، وهو رسالة مطبوعة من دار التذمرية ومتداولة. - قواعد أصولية مستمدة من سورة النساء وتطبيقاتها الفقهية، تأليف: الدكتور محمد شريف مصطفى، بحث منشور في المجلد ب ا، العدد:ء، من المجلة

$$
\text { الأردنية في الدراسات الإسلامية. }
$$

- مشروع الاستدلال بالقرآن الكريم على المسائل الأصولية في تفسير الفخر الرازي، وهو مشروع علمي مقدم من طلاب الماجستير بجامعة الإمام

محمد بن سعود الإسلامية وبك أهـ 


\section{علاقة أصول الققه بالقرآن الكريم وعلومه}

- مشروع استدلال الأصوليين بالآيات القرآنية على المسائل الأصولية، مقدم من طلاب الماجستير بقسم الثريعة بجامعة الجوف.

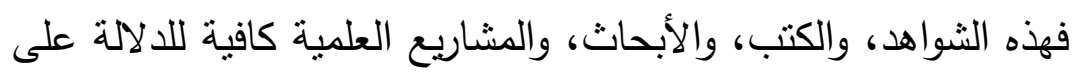
استمداد أصول الفقه من القرآن الكريم. الفرع الثاني: تملثّ كثير هن هسائل أصهل الفقه بالقرآن الكريم:

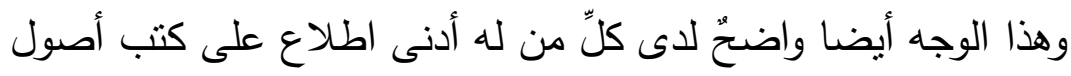
الققه، فإن القرآن الكريم يعتبر أول الأدلة المتفق عليها عند الأصوليين، ويتعرَّض أهل الأصول تحت باب الكتاب إلى تعريفه، وحجيته، وغير ذلك من المسائل التي لا تكاد تخفى على أحد.

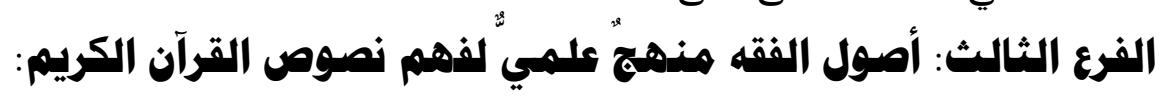

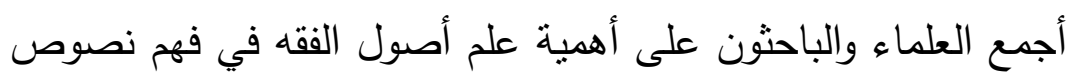
الثربعة، وتحديد دلالات الألفاظ، وطرق دلالتها على الأحكام؛ ففيه قواعد تربط جزئيات النصوص بكلياتها، وعامها بخاصها، ومطلقها بمقيدها، ومنطوقها

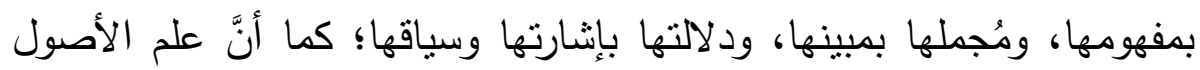
يشتمل على جملة من قواعد علمية مؤصمَّلة لدفع التعارض الظاهري عن الآيات القرآنية، ومنع المتطفلين من توظيف نصوص القرآن في غير مراد الثارع.

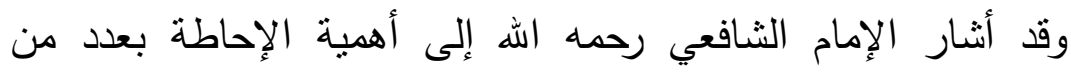
الأمور في فهم كتاب الله؛ وهي جُلُّها من مباحث علم أصول الفقه؛ حيث يقول: "لا يحلّ لأحد أن يفتي في دين اللَّه إلا رجلًَ عارفًا بكتاب اللَّه، بناسخه

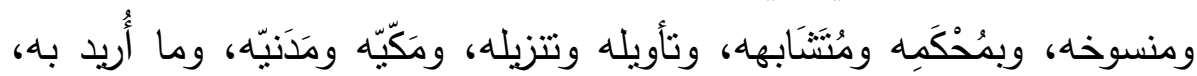

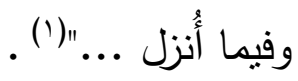

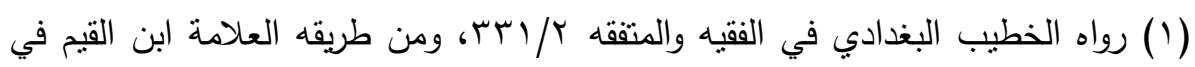

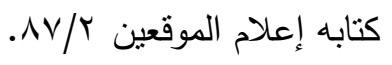




\section{علاقة أصول الققه بالقرآن الكريم وعلومه}

ونظرًا لأهمية علم أصول الفقه في فهم القرآن، وتركيز كثثر من مسائله على خدمة النص الثرعي، اختار كثير من العلماء القول بأن موضوع علم أصول الفقه هو النص الثرعي؛ وبتعبير آخر: معرفة الأدلة الثرعية الكلية

$$
\text { التي توصل إلى الأحكام الثرعية'(1). }
$$

يقول شيخ الإسلام ابن تيمية رحمه اله: "المقصود من أصول الفقه أن

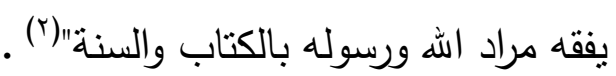

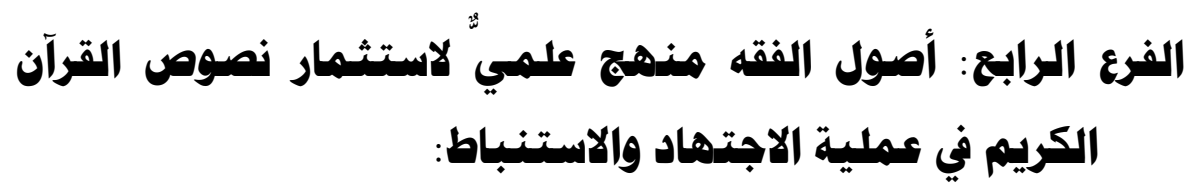

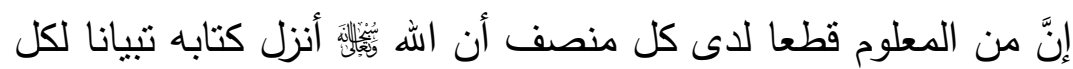
شيء، وأوحى إلى رسوله إلى القرآن العظيم، ومن بيان الرسول الكريم مجموعة من النصوص تتمثل فيها شريعة كاملة، ولكن هذه النصوص على كثرتها لم تتضمن التتصيص على حكم كل ما يحدث في مستقبل الأيام تفصيلا؛ فكان لا بد من شيء آخر غير النصوص يوظٍّف هذه النصوص في استتباط أحكام الحوادث غير المنصوصة، ويحدد لكل واقعة حكمها الذي يلائمها؛ وإنَّ مما لا شكَّ فيه أن العقول متفاوتة، والمدارك منباينة، والأفهام مختلفة، فلو ترك الباب مفتوحا لكل راغب، لحصل خلط كبير ، وفساد عظيم، ولاضطرب أمر هذه الشربعة، فكان من الضروري وضع قواعد يسير عليها من أراد استتباط الأحكام الثرعية من الأدلة القرآنية، والنصوص النبوية؛ ولهذا وضع القائمون على شريعة الله، القادرون على ولوج

(1) انظر: المستصفى للغزالي ص: ج، 9، وعلم أصول الفقه للاكتور عبد العزيز الربيعة

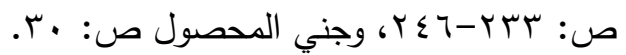

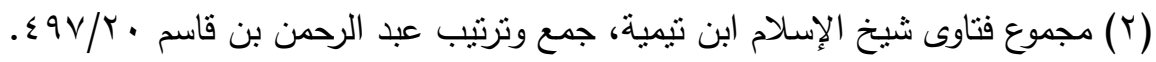




\section{علاقة أصول الققه بالقرآن الكريم وعلومه}

هذا الميدان قواعد تضبط عملية استتباط الأحكام الثرعية من أدلتها، وقد

عرفت هذه القواعد بأصول الفقه(').

يقول العلامة شهاب الدين القرافي المالكي: "لولا أصول الققه لم يثبت

من الثريعة قليل ولا كثير، فإن كل حكم شرعي لا بُدَّ له من سبب موضوع، ودليل يدل عليه وعلى سبيه، فإذا ألغينا أصول الفقه ألغينا الأدلة، فلا ييقى لنا حكم ولا سبب، فإن إثبات الثرع بغير أدلته، وقواعدها بمجرد الهوى خلاف

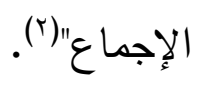

ويقول جمال الدين الإسنوي -مبيًِّا أهمية علم أصول الفقه: "إذْ هُوَ

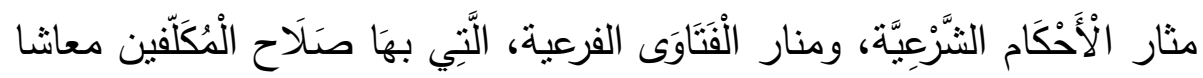

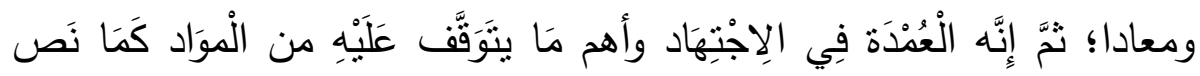

عَلَيْهِهِ الْعلمَاءع" (r).

ويقول العلامة بدر الدين الزركثي: "فأن أولى ما صُرفت الهمم إلى

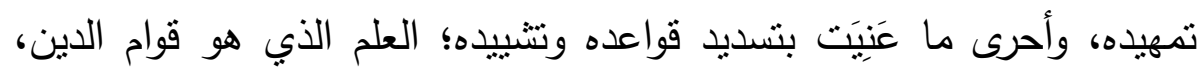

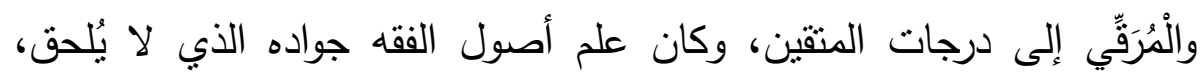

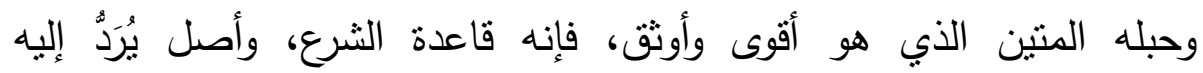

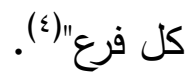

والخلاصة: أن أصول الفقه ليس منهجا لفهم نصوص القرآن الكريم والسنة

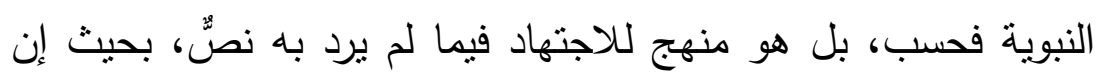

(1) انظر : علم أصول الفقه للاكتور عبد العزيز الربيعة ص: 10-1 م، وجني المحصول ص:

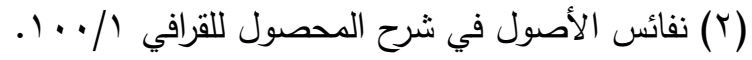

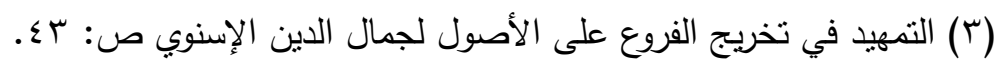

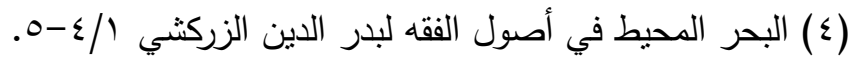




\section{علاقة أصول الققه بالقرآن الكريم وعلومه}

قواعده الإفهامية والتزيلية إنما وُضعت لهذا المقصد، وهو معالجة النوازل والمستجدات، يقول الإمام أبو حامد الغزالي: "ينظر الأصولي في

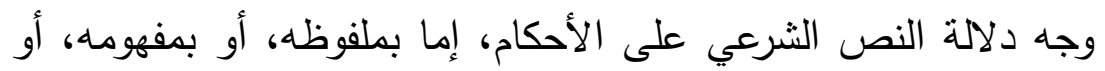
بمعقول معناه ومستتبطه"(')؛ فعلم الأصول كما بصفه أرباب النظر: " قاعدة الأحكام الثرعية، وأساس الفتاوى الفرعية، وركيزة الاجتهاد والتخريج، وقانون العقل والترجيح " (؟).

* $\quad * \quad * \quad * \quad * \quad *$

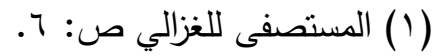

(Y) نهاية السول شرح منهاج الأصول للإسنوي / (1) 


\section{الإطلب الثاني}

\section{علاقة أصهول الفقه بعلوم القرآن}

سأتعرض لإبراز علاقة العلمين من خلال الفروع الثلاث التالية:

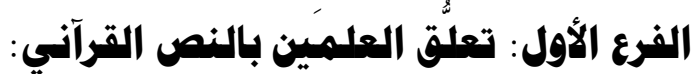

عدَّ الإمام أبو حامد الغزالي علم الأصول من جملة العلوم التي تتعلق

بالقرآن(')؛ وقد سبق في المطلب الأول أوجه عديدة على تقرير تعلق علم الإماتو أصول الفقه بالقرآن الكريم؛ وأما تعلق علوم القرآن بالقرآن الكريم، فإنَّ مجرد تصور اسمه يكفي في تقرير هذا المطلب؛ وإن مما يشهد على تعلق العلمين بالقرآن الكربم: تعلق موضوعهما بالقرآن الكربم؛ حيث تقدَّم أن موضوع علم

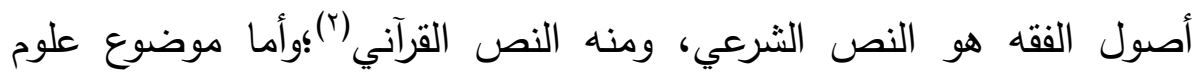
القرآن، فهو القرآن الكريم من حيث نزوله، وجمعه، وقراءاته، وتقسيره، وناسخه ومنسوخه، وأسباب نزوله، ونحو ذلك (r).

\section{الفرع الثاني: اشتزاط العلم بأصول الفقه في التفسير:}

عدَّ العلامة ابن جزي الكلبي رحمه الله علم أصول الفقه من أهم أدوات تقسير القرآن الكريم؛ حيث قال: "وأما أصول الفقه فإنها من أدوات تفسير القرآن ... وإنها لنعم العون على فهم المعاني وترجيح الأقوال؛ وما أحوج المفسر إلى إلى معرفة النص والظاهر، والمجمل والمبين، والعام والخاص، والمطلق والمقيد، وفحوى الخطاب ولحن الخطاب ودليل الخطاب، وشروط النسخ، ووجوه

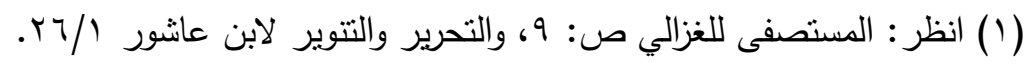

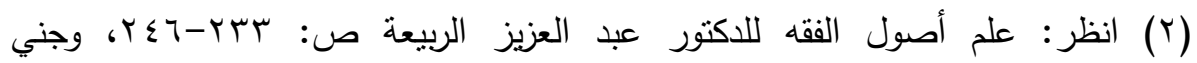

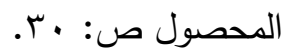

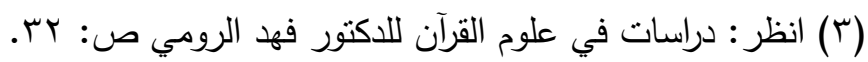




\section{علاقة أصول الفقه بالقرآن الكريم وعلومه}

التعارض، وأسباب الخلاف، وغير ذلك من علم الأصول"('). كما تعرض العلامة الثيخ محمد الطاهر بن عاشور في مقدمة تفسيره لبيان أوجه كون علم أصول الفقه أداة لتفسير كلام اله سبحانه وتعالى؛ وذللك

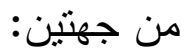

"إهداهما: أن علم الأصول قد أُودعثْ فيه مسائلُ كثيرة، هي من طرق استعمال كلام العرب، وفَهم موارد اللغة، أهمَل التتبيه عليها علماء

العربية، مثل: مسائل الفحوى، ومفهوم المخالفة ...

ثانيهـا: أن علم الأصول يضبط قواعد الاستتباط، ويُفصح عنها، فهو آلة

للمفسِّر في استتباط المعاني الثرعية من آياتها"(؟).

ومَنْ رجع إلى كتب علوم القرآن عموما، والتفسير خصوصا، لوجد أنها

مليئة بالمادة الأصولية، وخصوصا كتب أحكام القرآن، وسيأني مزيد توضيح لهذا الأثز في الفرع التالي. باله

\section{الفرع الثالث: كثرة المسائل المثتركة بين علمي أصول الفقه وعلوم القرآن:}

بالغ بعض الباحثين في تقرير هذا الفرع، حتى قال: إن أصول التفسير

ليس سوى مباحث أصولية؛ وكل ما ذُكر في كتب أصول التفسير بدءا بكتاب الحارث المحاسبي (فهم القرآن)، ومرورا بمقدمات بعض كتب التقسير ، وبمقدة ابن تيمية في أصول التفسير، إلى كتب علوم القرآن المتأخرة، وبكتب أصول التفسير الحديثة والمعاصرة =كلها لا تزيد عن مباحث أصولية متعلقة بفهم القرآن الكريم؛ إلا ما يضيفه بعضهم لنصرة منهج يتبعه ومدرسة يتعصب لها !!

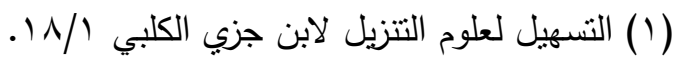

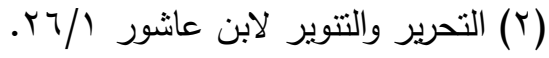




\section{علاقة أصول الفقه بالقر آن الكريم وعلومه}

وكل محاولات الفصل بين علم أصول الفقه وأصول التفسير محاولات

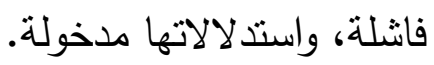

وأما اثتمال كتب أصول التفسير على مباحث نادرة مما هي ليست التهات

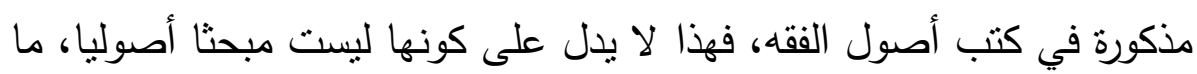

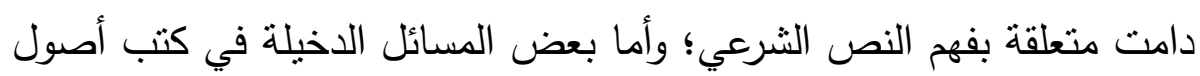

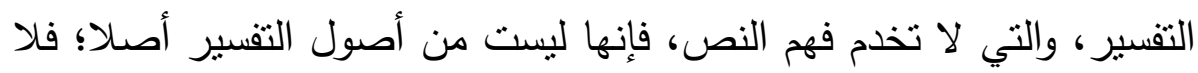
يضر عدم ورودها في كتب الأصوليين (').

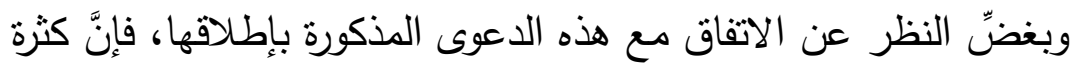

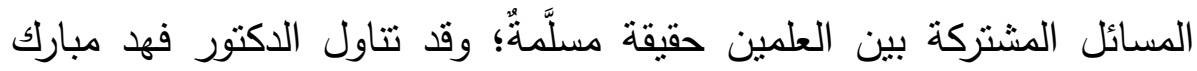

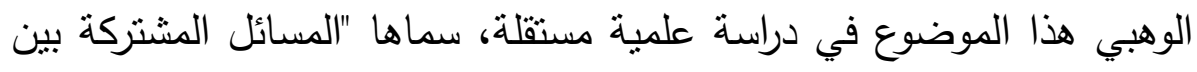
علوم القرآن وأصول الفقه"؛ وهي مطبوعة من مركز تفسير الدراسات القرآنية

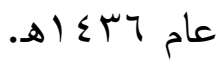
وسأورد هنا خلاصة ما ورد في نتائج الدراسة الدذكورة؛ حيث قال الباحث:

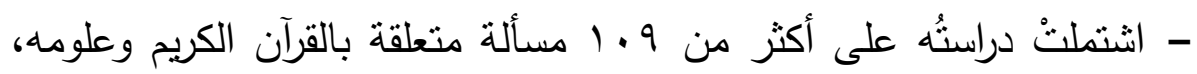

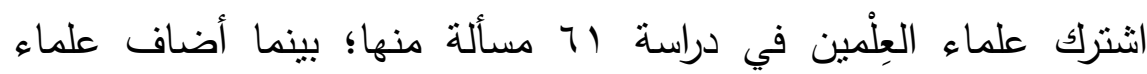
أصول الفقه Y T مسألة، وأضاف علماء علوم القرآن 17 مسألة.

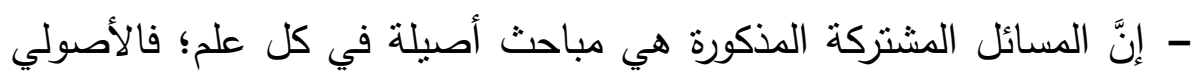
يبحث عنها من حيث تعلقها بكيفية المستقيد، ونتأثيرها في استخراج الأحكام

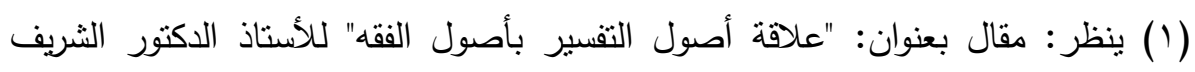

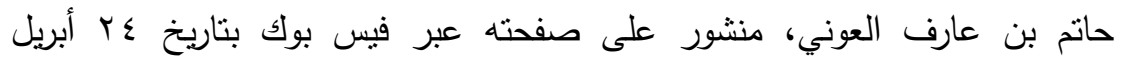

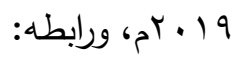
https://www.facebook.com/Alruny/posts/1 + 1 ovrVVr

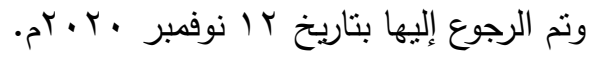




\section{علاقة أصول الفقه بالقرآن الكريم وعلومه}

الذي من أجله وُضِحَ علم أصول الفقه؛ بينما كتب علوم القرآن تبحث هذه المسائل لإعانة المفسر؛ وقد أضاف الباحث عدة فوارق بين دراسة علماء

أصول الفقه وبين دراسة علماء علوم القرآن للمباحث المشتركة(1).

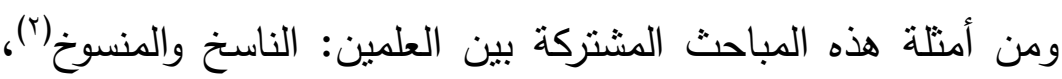

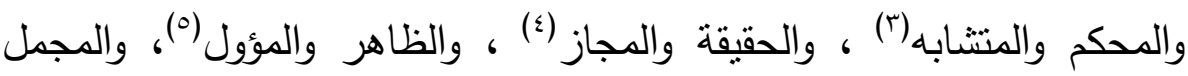

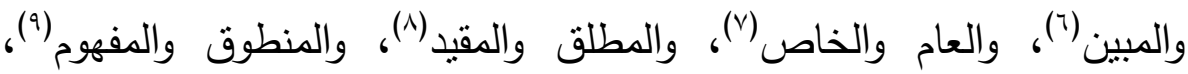
وغير ذلك.

(1) انظر: المسائل الششتركة بين علوم القرآن وأصول الفقه للاكتور فهد الوهبي

$$
\text { ص: }
$$

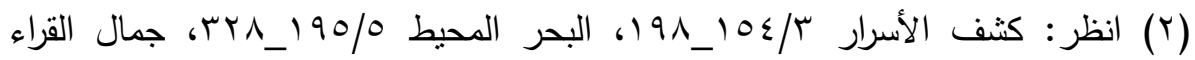

$$
\text { صaro_ }
$$

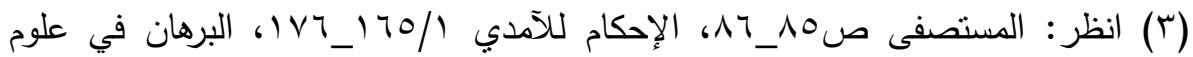

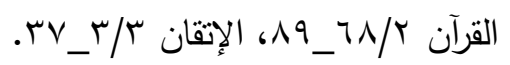

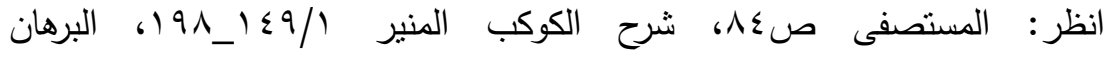

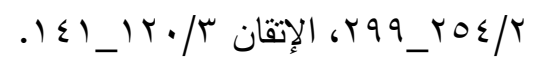

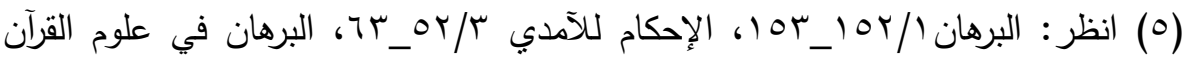

$$
\text { ( T) }
$$

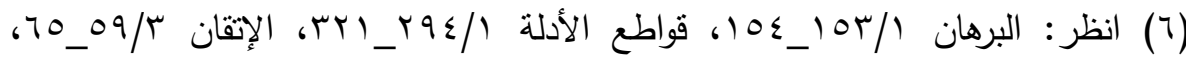

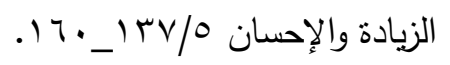

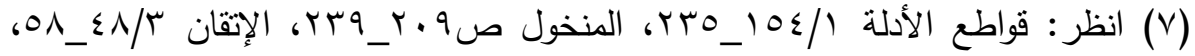

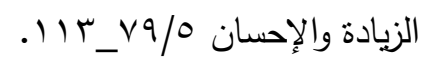

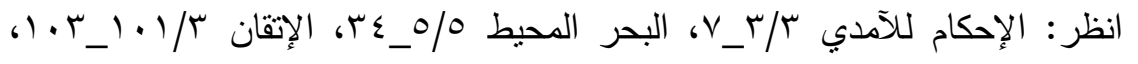

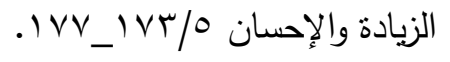

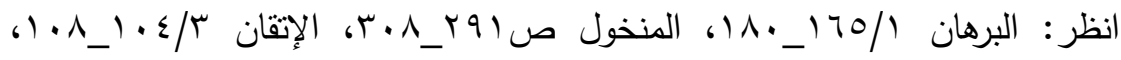

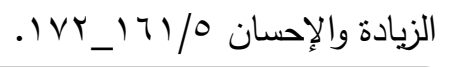




\section{علاقة أصول الفقه بالقرآن الكريم وعلومه}

وقد كان من آثار كثرة المباحث المشتركة بين العلمين: بروز علماء

برعوا في العلمين، وصنَّفوا فيهما؛ وأذكر هنا بعض الأمثلة على ذلك في

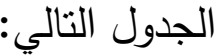

\begin{tabular}{|c|c|c|c|}
\hline اسم هؤلفه في أصول & اسم هؤلفه في علوم & اسم العلَم & $P$ \\
\hline الرسالة & أحكام القرآن جمع البيهقي & الإمام الثافعي & 1 \\
\hline الفصول في الأصول & أحكام القرآن & أبو بكر الجصاص & r \\
\hline المحصول & أحكام القرآن & أبو بكر ابن العربي & r \\
\hline المحصول & التفسير الكبير & فخر الدين الرازي & $\varepsilon$ \\
\hline المسودة ومباحث متفرقة & مقدمة في أصول التفسير & شيخ الإسلام ابن تيمية & 0 \\
\hline شرح مختصر الروضة & الإكسير في قواعد التفسير & نجم الدين الطوفي & 7 \\
\hline البحر المحيط وغيره & البرهان في علوم القرآن & بدر الدين الزركثي & V \\
\hline إرشاد الفحول & فتح القدير & بدر الدين الشوكاني & $\wedge$ \\
\hline الكوكب الساطع نظم جمع & الإتقان في علوم القرآن & جلال الدين السيوطي & 9 \\
\hline مقاصد الثريعة الإسلادية & التحرير والتتوير & محمد الطاهر بن عاشور & 1 . \\
\hline
\end{tabular}

ومما يشه لذلك أيضا: كثرة المادة الأصولية في كتب التفسير؛ ولهذا اعتى كثثر من الباحثين المعاصرين في دراساتهم العلمية بجمع المادة الأصولية من خلال كتب التفسير ؛ ومن أمثلتها ما يلي: 1- المسائل الأصولية في كتاب الجامع لأحكام القرآن، للقرطبي جمعًا ودراسة، للباحث: زين الدين أحمد بن محمد اليدالي (رسالة ماجستير

$$
\text { بجامعة الإمام). }
$$

r- محمد الأمين الثنقيطي والآراء الأصولية في تفسير أضواء البيان، 


\section{علاقة أصول الفقه بالقرآن الكريم وعلومه}

للباحثة: سعيدة بوفاغس (رسالة ماجستير في جامعة الأمير عبد القادر

بالجزائر ).

r- أصول الفقه ومنهج توظيفه في التفسير عند ابن الفرس من خلال كتابه أحكام القرآن، للباحث: محمد عبد الوهاب أبياط (رسالة دكتوراه في جامعة

محمد الخامس بالمغرب).

ع- المسائل الأصولية في تقسير الرازي مفاتيح الغيب (وفيها رسالتان

مسجلتان بجامعة الإمام).

* * * * * * * * 


\section{خاتمة}

\section{أهم النتتائج والتوصيات:}

\section{أولا: أهم النتائج:}

يعد علم أصول الققه من أبرز العلوم التي شكَّت محورًا تقاطعت فيه مجموعة من العلوم، مما أهَّله لأن يكون علما جامعا بين العلوم النقلية والعلوم العقلية، وبين علوم الفهم وعلوم الاستدلال، وعلوم الثربعة وعلوم النظر - (1)

إنَّ البحث في العلاقة بين العلوم يبرز وحدة المرجعية الثرعية لهذه العلوم، والغاية الأسمى لها، وهي معرفة مراد الله، للوصول إلى عبوديته

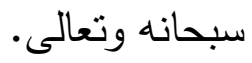
من أهم الجوانب التي برزتْ فيها علاقة علم أصول الفقه بالقرآن الكريم:

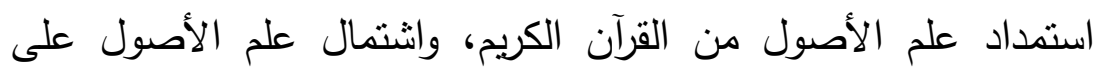
مباحث متعددة متعلقة بالقرآن الكريم، وأهمبة علم أصول الفقه في فهم نصوص القرآن الكربم، والاستتباط منها. من أهم الجوانب التي برزت فيها علاقة علم أصول الفقه بعلوم القرآن: تعلُّن العلمين بالنص القرآني، وكون معرفة علم أصول الفقه شرطا في بعرن تفسير القرآن، إضافة إلى وجود مباحث مشتركة كثيرة بين العلمين.

\section{ثانيا: التوصيات:}

الاهنمام بالدراسات التاريخية والعلاقات المشتركة بين العلوم الثرعية، وخاصة علم أصول الفقه، لأهمية ذلك في توسيع دائرة المهارات المعرفية لدى طالب علم الأصول. 


\section{علاقة أصول الفقه بالقرآن الكريم وعلومه}

القيام بدراسة علاقة علم أصول الفقه بمختلف العلوم والفنون، لكونه نقطة اتصال بين عدد من العلوم، وبيان مساحة الاشتراك، ومواضع الزيادة،

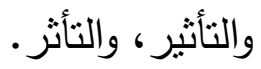

وآخر دعوانا أن الحمد لله رب العالمين، وصلى الله وسلم وبارك على ولى

نبينا محمد وعلى آله وصحبه أجمعين.

* $\quad * \quad * \quad * \quad * \quad *$ 


\section{فهرس البمث}

\section{أولا: فهرس الهسادر والمراجع:}

الإتقان في علوم القرآن. تأليف: عبد الرحمن بن أبي بكر، جلال الدين السيوطي. تحقيق: محمد أبو الفضل إبراهيم. نشر : الهيئة المصرية العامة

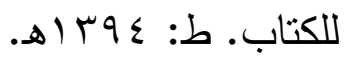

الإحكام في أصول الأحكام. تأليف: علي بن أبي علي بن محمد بن سالم الثعلبي الآمدي. تحقيق: عبد الرزاق عفيفي. نشر: المكتب الإسلامي، بيروت.

إعلام الموقعين عن رب العالمين. تأليف: أبي عبد الله محمد بن أبي بكر المعروف بابن قيم الجوزية. تحقيق: أبي عبيدة مشهور حسن سلمان. نشر :

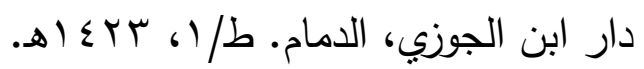
البحر المحيط في أصول الفقه. تأليف: أبو عبد الله بدر الدين محمد بن

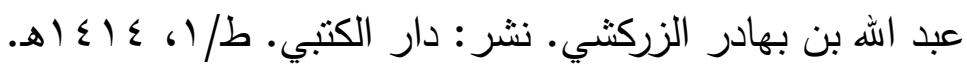
البرهان في أصول الققه. تأليف: عبد الملك بن عبد الله بن يوسف بن بن محمد الجويني. تحقيق: صلاح بن محمد بن عويضة. نشر : دار الكتب

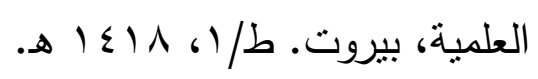
البرهان في علوم القرآن. تأليف: أبي عبد الهه بدر الدين محمد بن عبد الله بن بهادر الزركثي. تحقيق: محمد أبو الفضل إبراهيم. نشر: دار إحياء

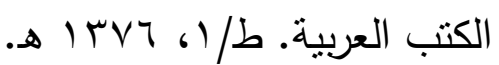
تجديد أصول الفقه: دراسة تحليلية نقدية لمحاولات المعاصرين،

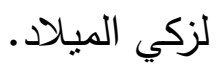


التحبير شرح التحرير في أصول الفقه. تأليف: علاء الدين أبي الحسن علي بن سليمان المرداوي الدمثقي الحنبلي. تحقيق: د. عبد الرحمن الجبرين، ود.عوض القرني، ود. أحمد السراح. نشر: مكتبة الرشد، الرباض.

التحرير والتتوير • تأليف: محمد الطاهر بن عاشور التونسي. نشر: الدار

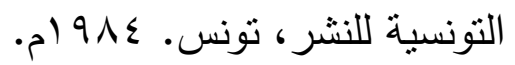
التسهيل لعلوم التتزيل. تأليف: أبي القاسم محمد بن أحمد المعروف بابن جزي الكلبي الغرناطي المالكي. تحقيق: د. عبد الله الخالدي. نشر : شركة

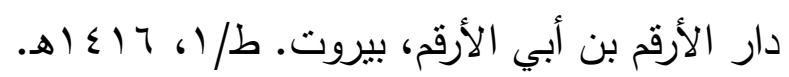
التمهيد في تخريج الفروع على الأصول. تأليف: جمال الدين عبد الرحيم ابن الحسن بن علي الإسنوي الثافعي. تحقيق: د. محمد حسن هيتو. نشر : مؤسسة الرسالة، بيروت. ط/ (ا، . . ـ اهـ. التوقيف على مهمات التعاريف. تأليف: زين الدين عبد الرؤوف المناوي القاهري. نشر: عالم الكتب، بيروت. ط/ إ، • (1 اهـ. جمال القراء وكمال الإقراء. تأليف: علي بن محمد الثافعي السخاوي. تحقيق: د. مروان العطيَّة - د. محسن خرابة. نشر: دار المأمون للتراث،

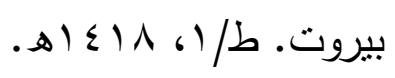

جَنْي المحصول في التعريف بعلم الأصول. تأليف: ناصر عيسى أحمد البلوشي. نشر: إدارة البحوث التابعة لدائرة الثؤون الإسلامية والعمل

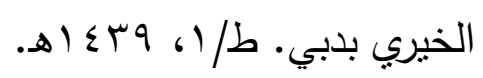
رسائل ابن حزم الأندلسي. تحقيق: إحسان عباس. نشر: المؤسسة العربية للدراسات والنشر بيروت. 
روضة الناظر وجنة المناظر في أصول الفقه على مذهب الإمام أحمد بن حنبل. تأليف: أبي محمد موفق الدين عبد الله بن أحمد بن قدامة الدمشقي

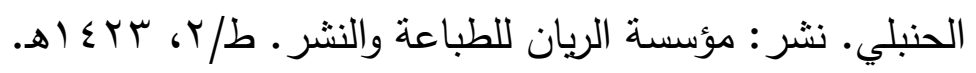
الزيادة والإحسان في علوم القرآن. تأليف: محمد بن أحمد الحنفي المكيّ، المعروف كوالده بعقيلة. تحقيق: أصل هذا الكتاب مجموعة رسائل جامعية

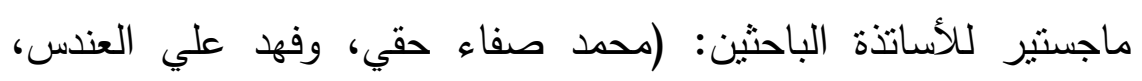
وإبراهيم محمد المحمود، ومصلح عبد الكريم السامدي، خالد عبد الكريم

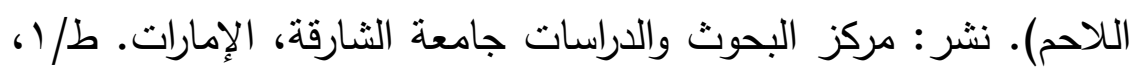
ه $1 \leq r V$ شرح الكوكب المنير • تأليف: تقي الدين أبو البقاء محمد بن أحمد الفتوحي المعروف بابن النجار الحنبلي. تحقيق: محمد الزحيلي ونزيه حماد. نشر:

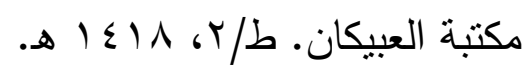
شرح مختصر الروضة. تأليف: سليمان بن عبد القوي الطوفي.

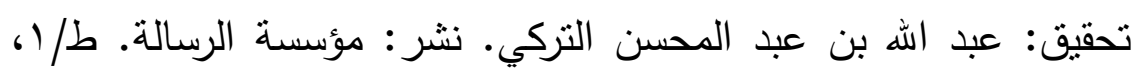

$$
\text { هـ } 1 \leq \cdot V
$$

علم أصول الفقه حقيقته ومكانته وتاريخه ومادته، تأليف: الدكتور عبد

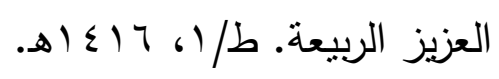

الفقيه والمتفقه. تأليف: الحافظ أبي بكر أحمد بن علي الخطيب البغدادي. تحقيق: أبي عبد الرحمن عادل الغرازي. نشر: دار ابن الجوزي، الدمام.

$$
\text { طـ }
$$

قواطع الأدلة في الأصول. تأليف: منصور بن محمد بن عبد الجبار السمعاني التميمي الحنفي ثم الثافعي. تحقيق: محمد حسن اسماعيل

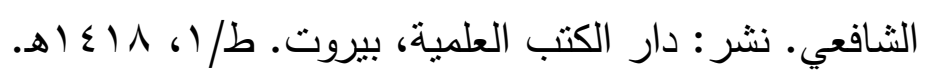


كثف الأسرار شرح أصول البزدوي. تأليف: عبد العزيز بن أحمد بن محمد، علاء الدين البخاري الحنفي. نشر: دار الكتاب الإسلامي. بدون طبعة وبدون تاربخ. الكليات (معجم في المصطلحات والفروق اللغوية) تأليف: أبي البقاء أيوب ابن موسى الكفوي الحنفي. تحقيق: عدنان درويش، ومحمد المصري. نشر : مؤسسة الرسالة، بيروت.

اللفظ المعقول في بيان تعريف الأصول للشيخ محمد بن أبي بكر الحنفي

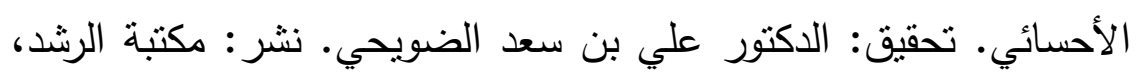

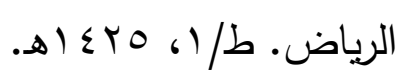
مجموع الفتاوى لشيخ الإسلام ابن تيمية. جمع وترتيب: عبد الرحمن بن قاسم. نشر : مجمع الملك فهد لطباعة المصحف الثريف بالمدينة المنورة. هـ 17

المسائل المشتركة بين علوم القرآن وأصول الفقه وأثرها في التفسير ـ تأليف: د.فهذ بن مبارك الوهبي. نشر: مركز تفسير للاراسات القرآنية، الرياض.

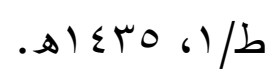
المستصفى من علم الأصول. تأليف: أبي حامد محمد بن محمد الغزالي. تحقيق: محمد عبد السلام. نشر: دار الكتب العلمية، بيروت. طا له ال، س إن (1)

المطلق والمقيد، تأليف: الدكتور حمد بن حمدي الصاعدي. نشر: عمادة

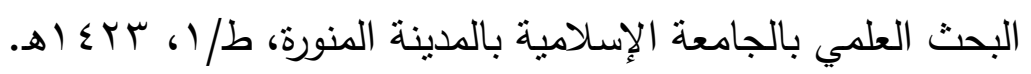
معجم مصطلحات العلوم الثرعية. إصدار : مدينة الملك عبد العزيز للعلوم

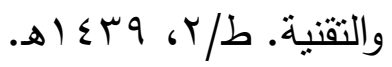


مقاييس اللغة. تأليف: العلامة أبي الحسين أحمد بن فارس. تحقيق: عبد السلام محمد هارون. نشر: دار الفكر، بيروت. 99 با هـ. مناهل العرفان في علوم القرآن. تأليف: محمد عبد العظيم الزُّرْقاني. نشر: مطبعة عيسى البابي الحلبي وشركاه. ط/ r. المنخول من تعليقات الأصول. تأليف: محمد بن محمد الغزالي. تحقيق: الدكتور محمد حسن هيتو. نشر: دار الفكر المعاصر، بيروت

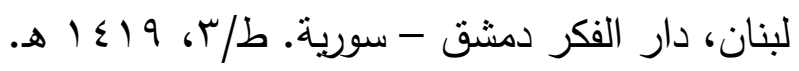
نفائس الأصول في شرح المحصول. تأليف: شهاب الدين أحمد بن إدريس القرافي. تحقيق: عادل أحمد عبد الموجود، وعلي محمد معوض.

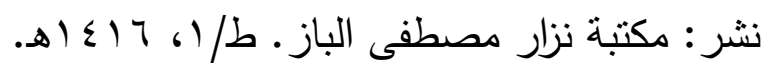
نهاية السول شرح منهاج الأصول. نأليف: جمال الدين عبد الرحيم بن الحسن بن علي الإسنوي الثافعي. نشر: دار الكتب العلمية، بيروت. ط

* $\quad * \quad * \quad * \quad * \quad *$ 
علاقة أصول الفقه بالقرآن الكريم وعلومه

\section{فهرس الموضوعات}

\begin{tabular}{|c|c|}
\hline الصفحة & الموضوعات \\
\hline $109 r$ & مقدمة البحث: \\
\hline $109 \varepsilon$ & أهمية الموضوع \\
\hline $109 \varepsilon$ & أهداف البحث \\
\hline 1090 & أسئلة البحثث \\
\hline 1090 & خطة البحث: \\
\hline 1090 & ج البحث: \\
\hline 1097 & تمهيد: في توضيح مفردات البحث \\
\hline 1097 & أولا: تعريف القرآن الكريم \\
\hline 1097 & ثنانيا: تعريف أصول الفقه باعتبار معناه اللقبي \\
\hline 1097 & ثنالثا: تعربف علوم القرآن باعتبار معناه اللقبي \\
\hline 1091 & رابعا: تعربف العلاقة \\
\hline 1099 & المطلب الأول: علاقة أصول الققه بالقرآن الكريم \\
\hline 1099 & الفرع الأول: استمداد علم أصول الفقه من القرآن الكربم \\
\hline $17 \ldots$ & الكريمع الثاني: تعلُّق كثير من مسائل أصول الفقه بالقرآن \\
\hline 17. & القرع الثالث: أصول الفقه منهجُ علميٌٌ لفهم نصوص \\
\hline $17 \cdot 1$ & الفرع الرابع: أصول الفقه منهج عليهّ لاستثمار \\
\hline
\end{tabular}




\section{علاقة أصول الفقه بالقرآن الكريم وعلومه}

\begin{tabular}{|c|c|}
\hline الصفحة & الموضوعات \\
\hline $17 \cdot \varepsilon$ & المطلب الثاني: علاقة أصول الفقه بعلوم القرآن \\
\hline $17 \cdot \varepsilon$ & الفرع الأول: تعلُّق العلمَين بالنص القرآني \\
\hline 17.0 & الفرع الثالث: كثرة المسائل المشتركة بين علمي أصول \\
\hline 171 & خاتمة: أهم النتائج والتوصيات \\
\hline 171. & أولا: أهم النتائج \\
\hline 171 & ثنانيا: التوصيات \\
\hline $171 \%$ & فهرس البحث: \\
\hline $171 r$ & أولا: فهرس المصادر والمراجع \\
\hline 1718 & ثانيا: فهرس الموضوعات \\
\hline
\end{tabular}

تَََّّ بحمد الله -تعالى - وتوفيقه والحمد اله ربِّ العالمين. 